\title{
ICONOGRAFIA DO TRABALHO EM GRAMADO-RS
}

Iraci Casagrande Koppe ${ }^{1}$

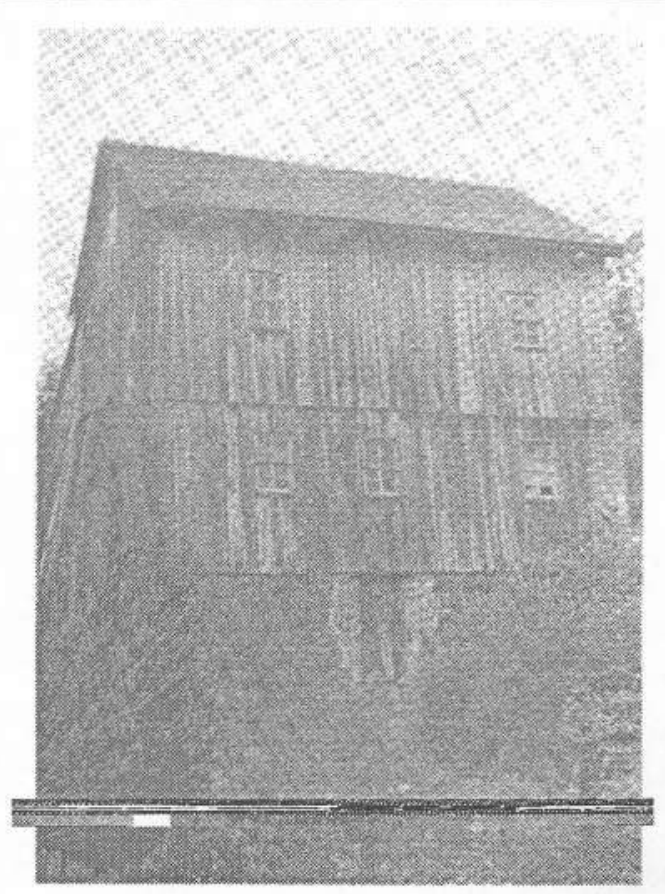

1. Antigo moinho Cavichon movido à energia hidráulica. Construído no início deste século, em Linha Bonita, sete quilômetros do Centro de Gramado. Cada colônia possuía seu moinho próprio, que transformava os cereais em farinha. O moinho Cavichon voltou a funcionar à eletricidade.

1 Pesquisadora e Historiadora de Gramado e Canela. Mantém coluna de história municipal no jornal local. As fotografias pertencem ao acervo de Iraci Casagrande Koppe e de Carlos Gilberto Drechler. 


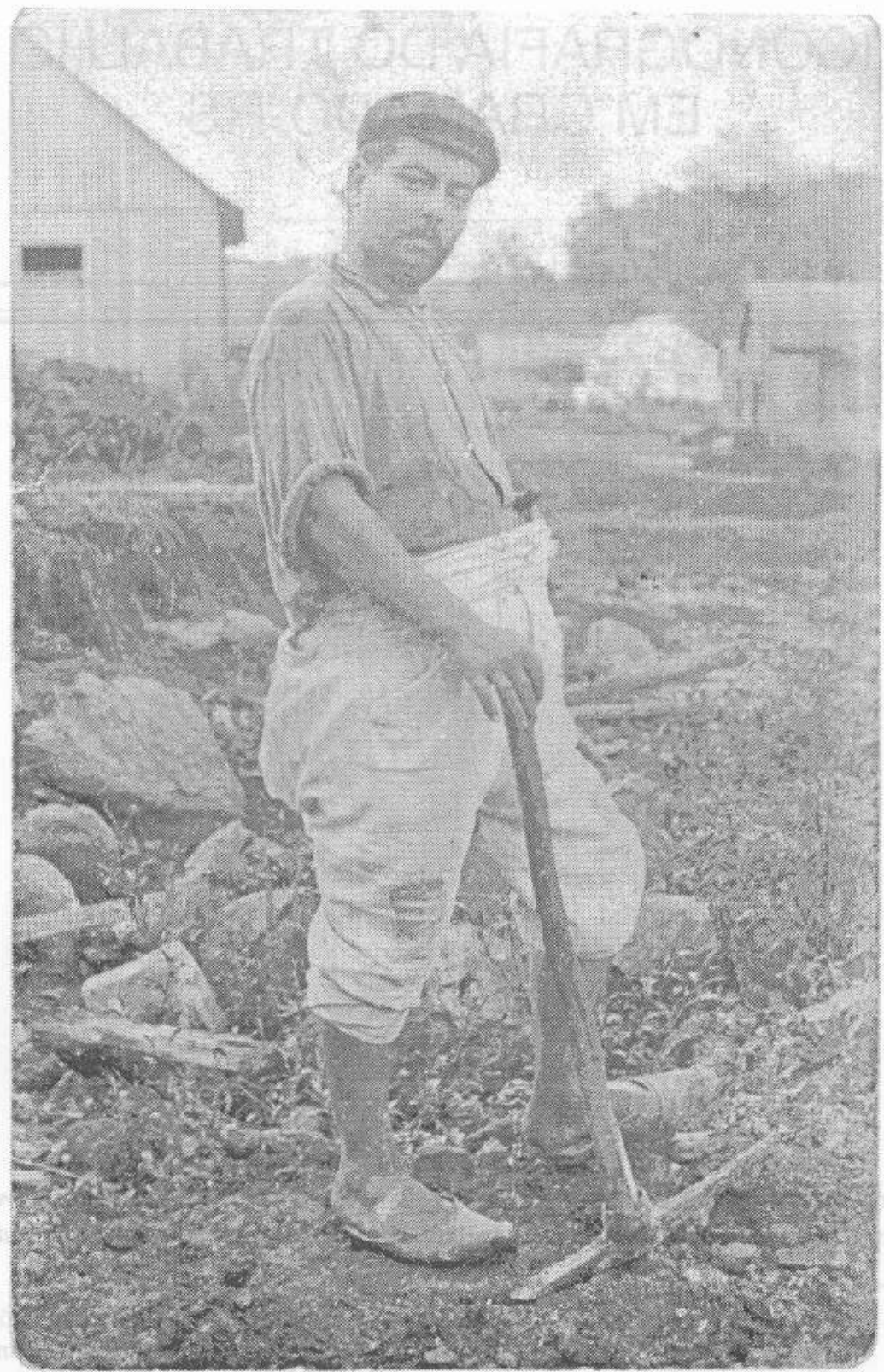

2. Construtor de estradas e ruas no inicio dos anos 20, em Gramado, ostentando com orgulho a picareta. 


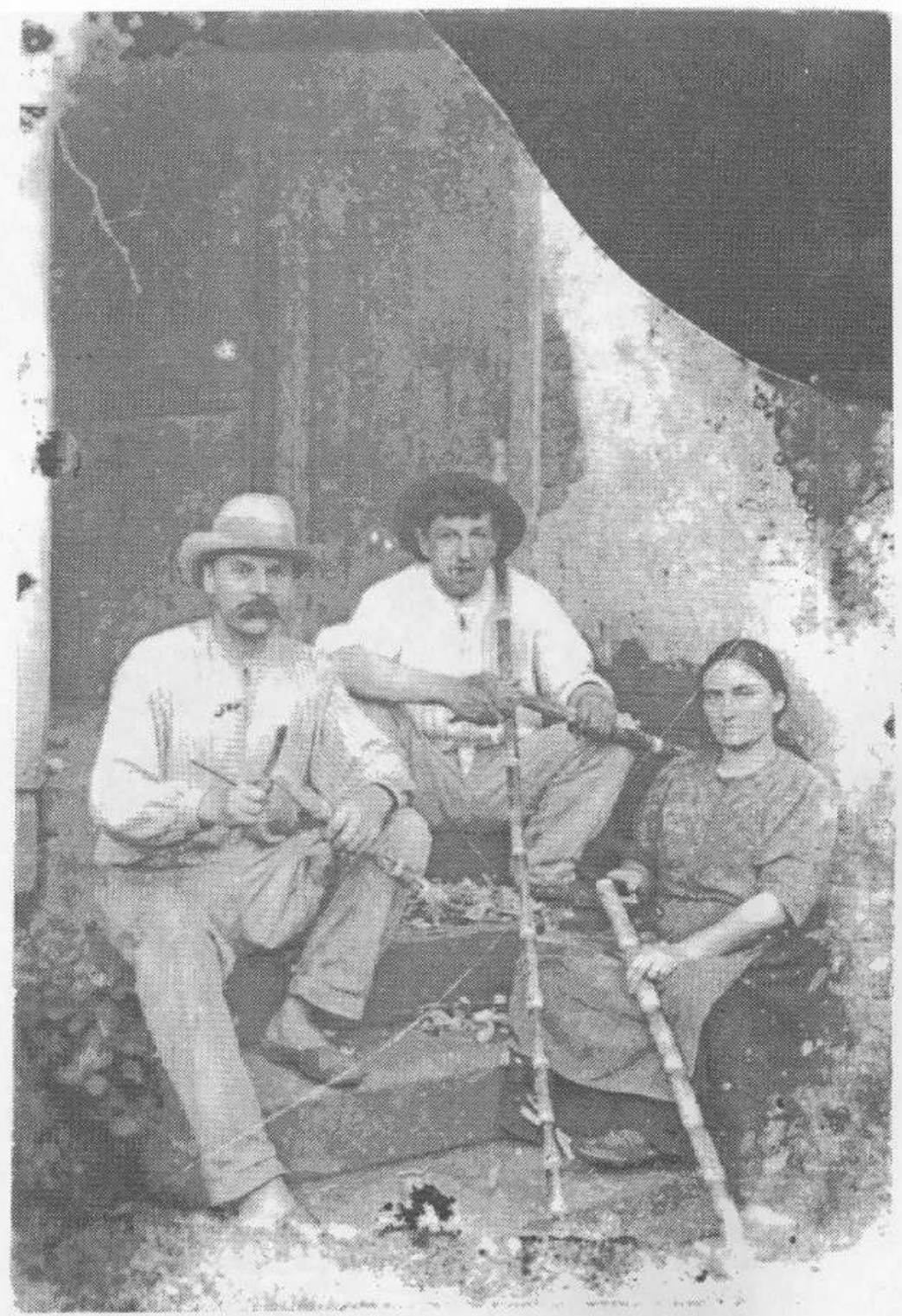

3. Alambiques produziam cachaça que era vendida nas bodegas ou vendas no interior de Gramado. Após um dia estafante de trabalho pesado a família Bohnember, em Linha Araripe, descansa e degusta saborosa cana de açúcar. (Negativo em vidro - 1918). 


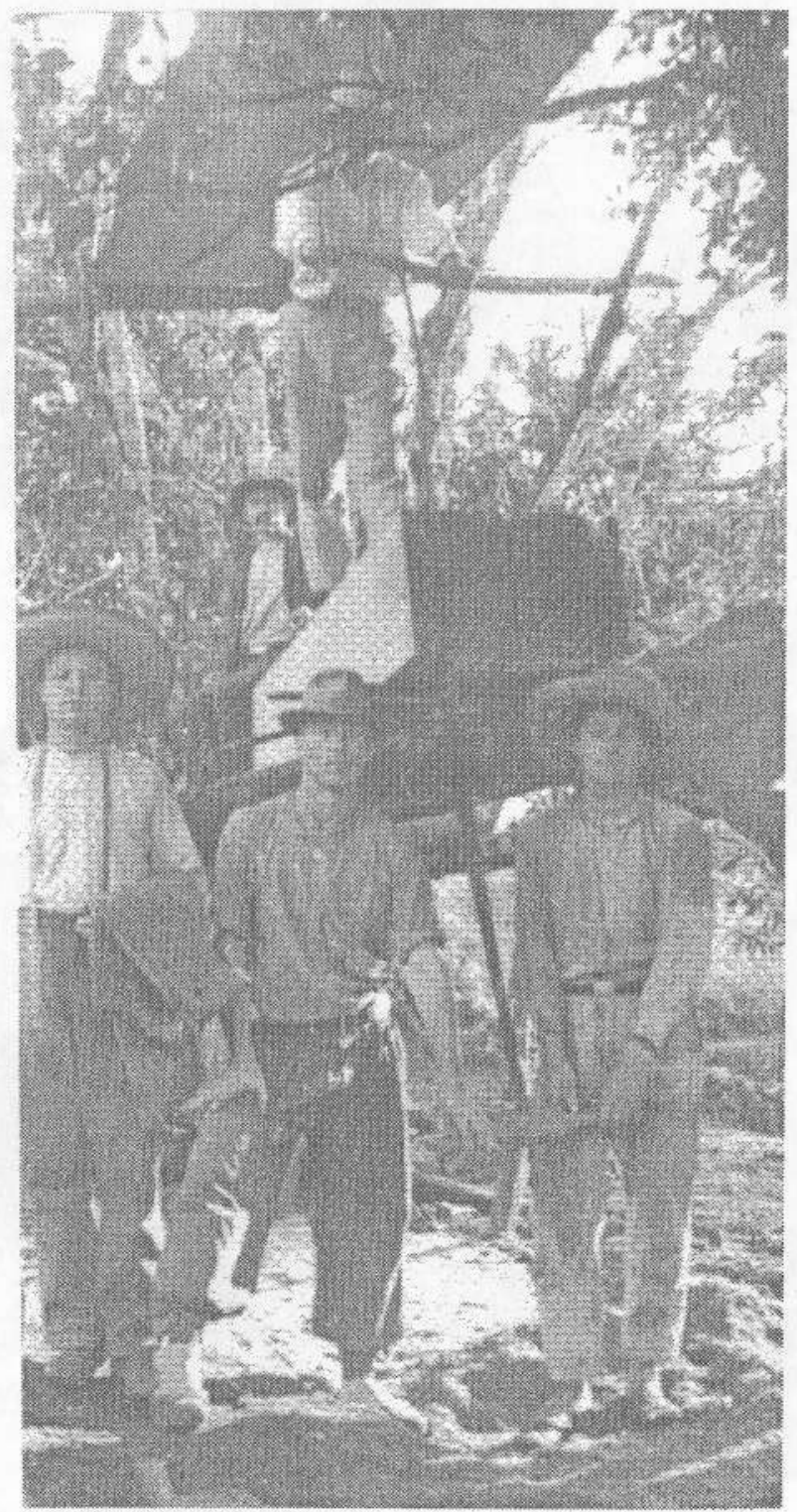

4. Imigrantes alemães e italianos trouxeram em sua bagagem cultural conhecimentos que facilitaram vencer as dificuldades para efetuar seu trabalho.

Foto de 1930, de primitivo sistema de serrar a madeira, em Linha Ávila. 


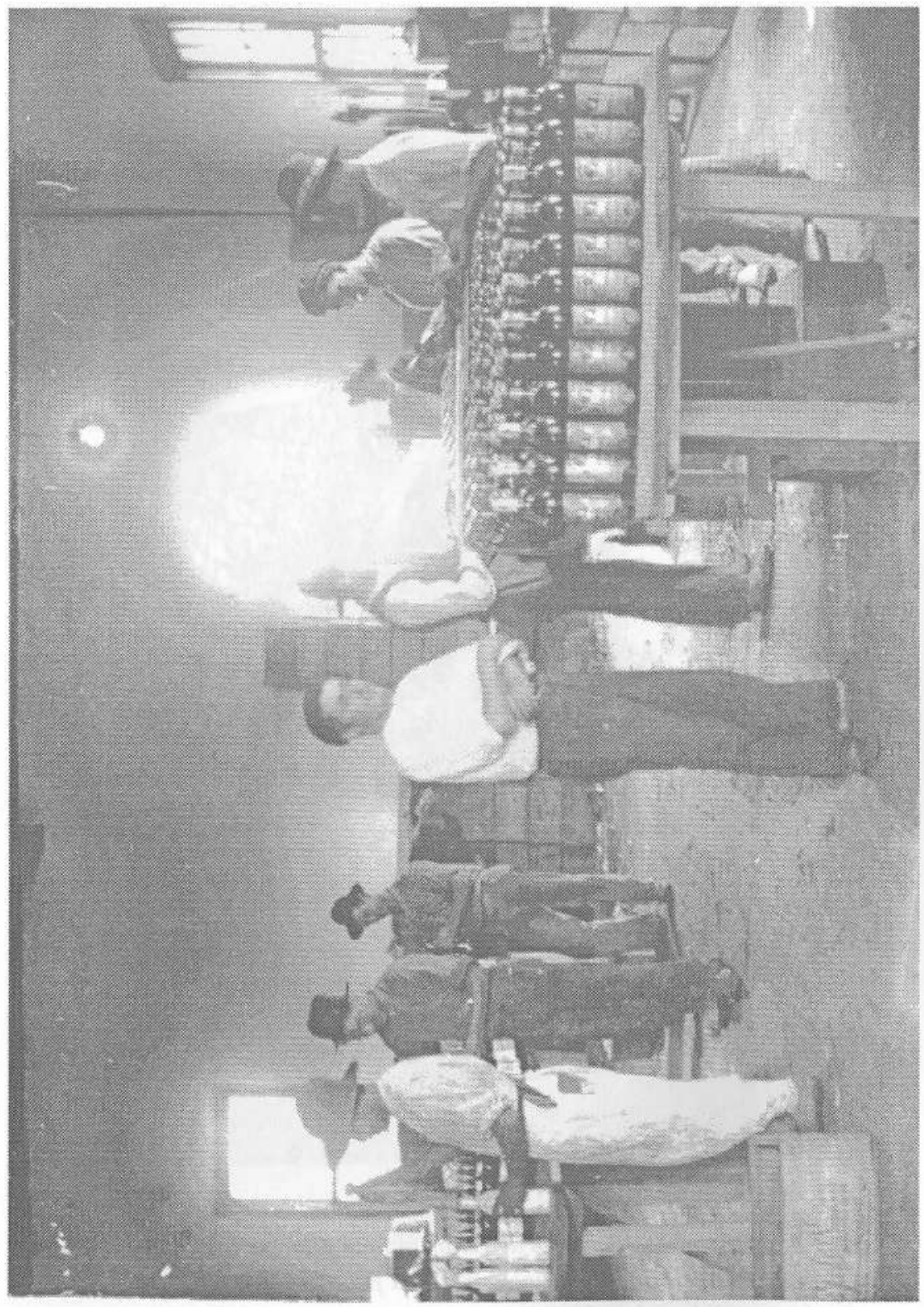

5. Vinícola Petronius, de Emílio Kunz, anos 30, setor de rotulação. $O$ vinho era embarcado em trem e vendido por todo Brasil. 


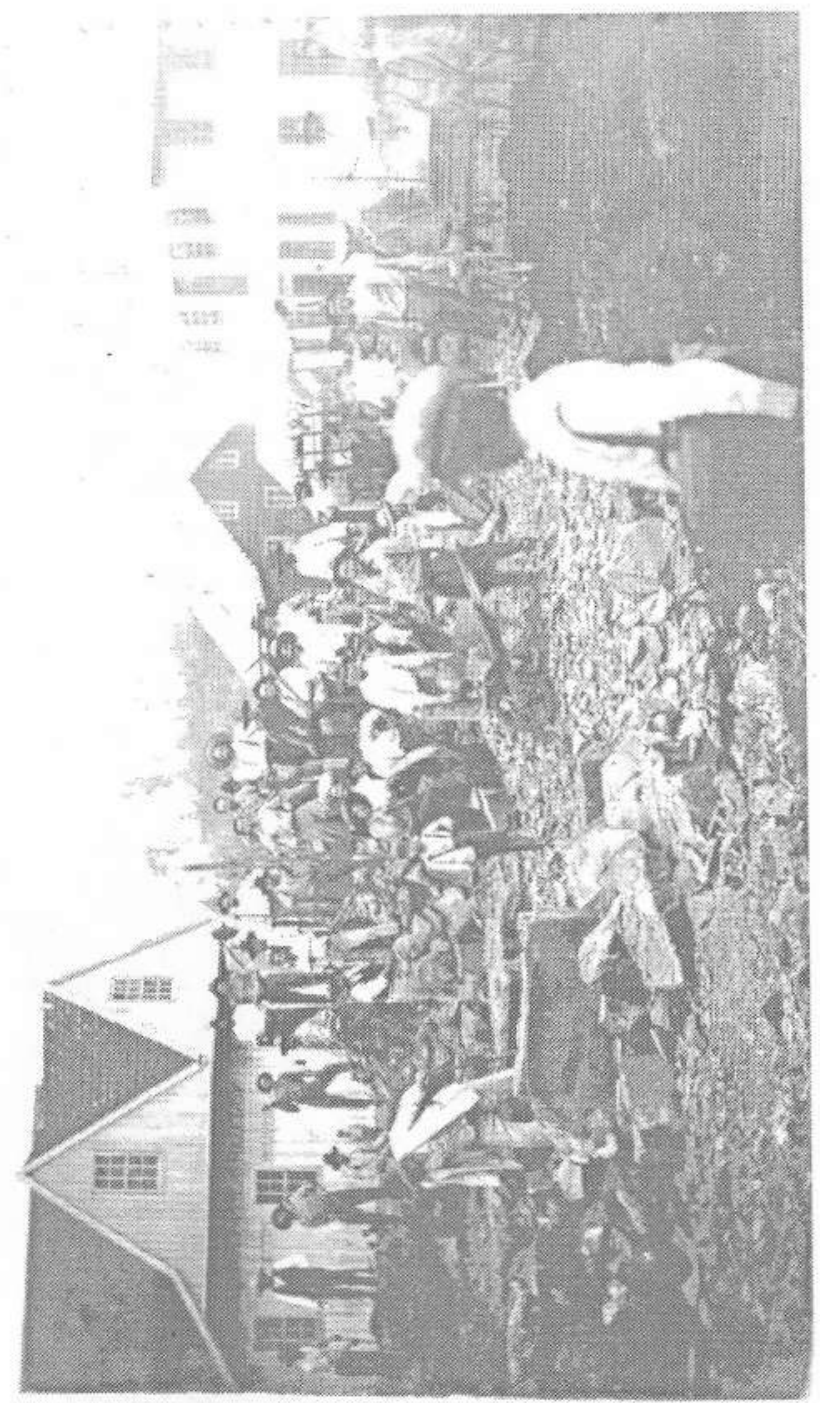

6. Gramado, atual praça no centro, inicios de 1930.

Os Legionários do Trabalho detonaram uma enorme laje de pedra, onde posteriormente foi construída a praça Major Nicoletti.

Os desprendidos pioneiros construíram as ruas com pás, picaretas, carrinhos de mão e enxadas. Após um dia de trabalho, muita lingüiça, pão e vinho, restauravam as energias para o dia seguinte.

Vê-se as três primeiras casas de comércio: Molhub, Benetti e Bordin 


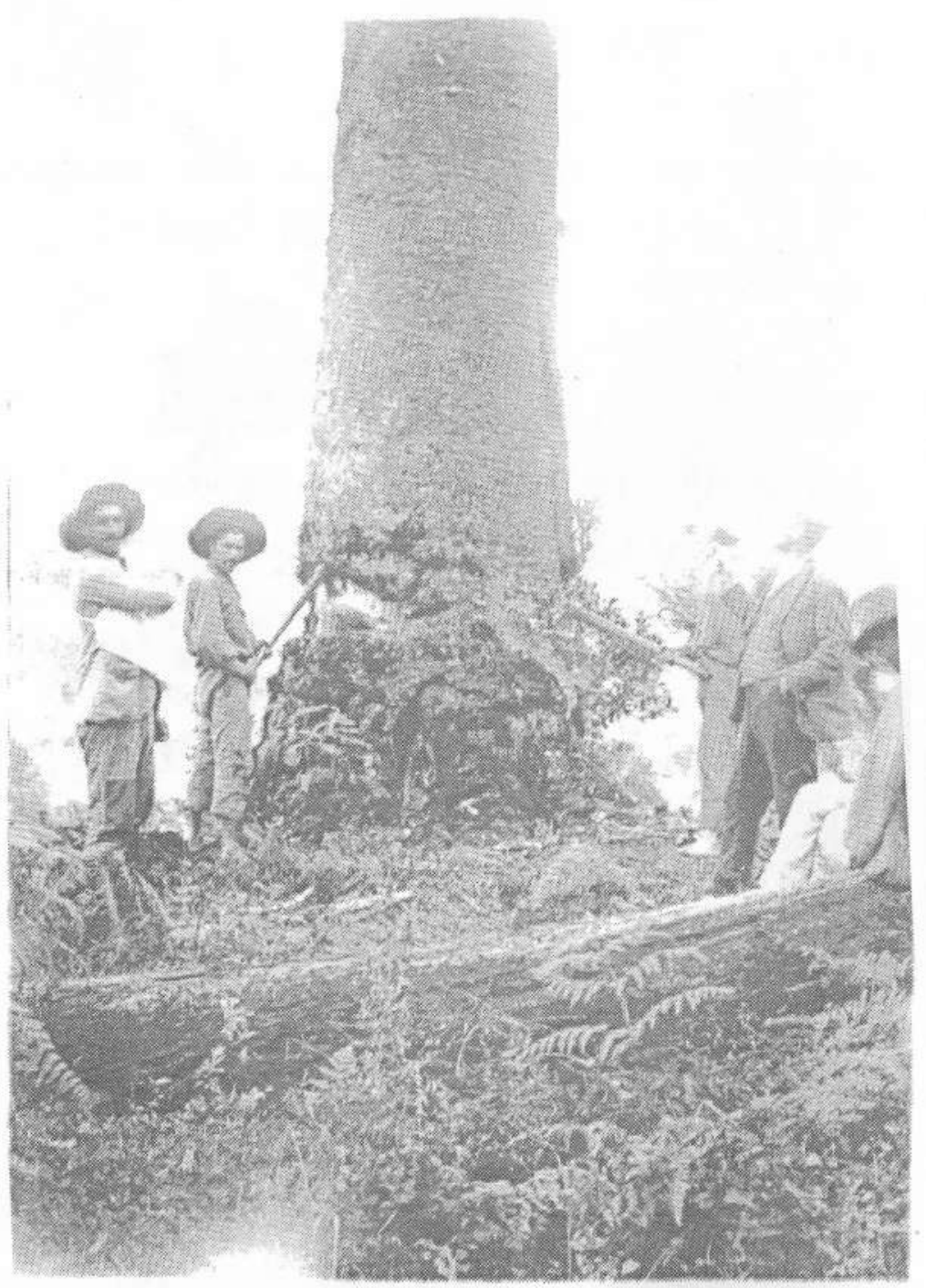

7. Foto de 1920. Os pinheiros eram abatidos tanto para dar lugar, como para fornecer as tábuas para a construçäo das casas. Os pinheiros eram abatidos por vários homens que se revesavam no uso do machado. 


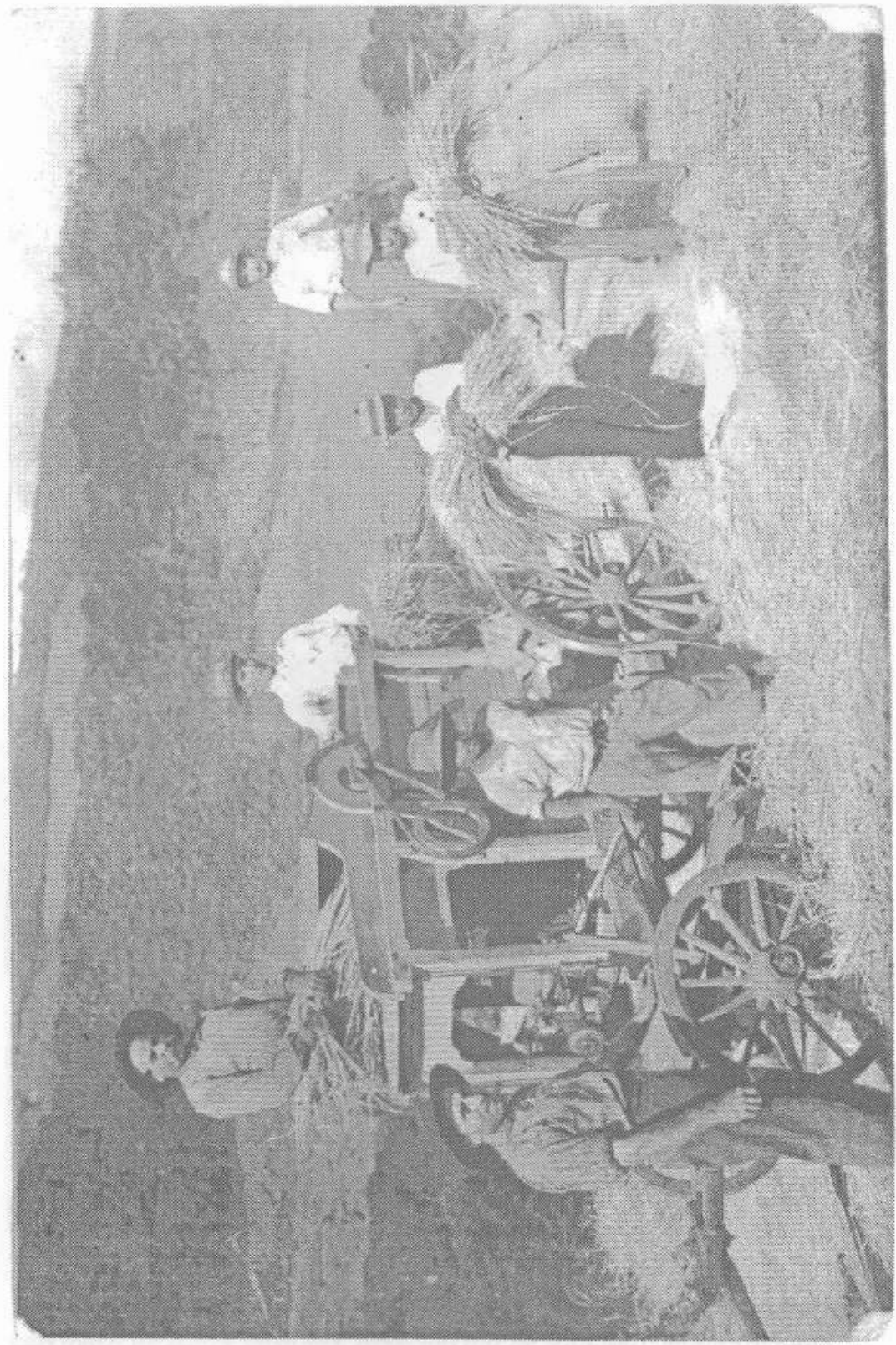

8. Debulhadeira de trigo, década de 1920 , puxada por traçäo animal e movida por motor a gasolina. 